\title{
Perceived Stress and Coping Resources among Male and Female Employees in Diverse Workforces
}

\author{
Ms. Shivani Datta ${ }^{1}$
}

\section{ABSTRACT:}

The present research work intended to study perceived stress and coping resources in diverse workforces. Diversity in workforce has been operationalized not only at micro level in terms of relative male-female numerical strength of the workforce in the organization but also at a macro level in terms of the relative male-female composition of different occupations that has led to gender typing of these occupations. Most previous gender based studies have sought to understand perceived workplace stress narrowly in terms of impact of gender alone. The present study extends the framework of prior research work by examining stress and coping resources as a function of Gender, Occupational Gender Typing (Gender Atypical/Gender Neutral or Non Atypical) and Proportional (Male-Female) Numerical Strength at workplace (Tokens/Non Tokens), with an examination of different groups of Males and Females in Gender Atypical and Gender Neutral/Non Atypical occupations as numerical Tokens and Non Tokens respectively. Total sample size was 250. Results depict that the complex interaction of Gender, Gender typing of Occupation and Male Female proportional numerical strength impact perceived stress and coping resources.

Keywords: Gender, Diversity, Stress, Coping resources

Diversity has been a much debated topic in management theory and practice in recent years, it were initially legal aspects, notably the avoidance of law suits, as well as changes in the labor market demographics(e.g. increased participation of women and minorities) that made it a subject of paramount importance for corporations.

The current form of the discursive theme of diversity increasingly emphasizes voluntary efforts (on the part of the organization) for enhancing inclusion as the ideal response to employee difference. Because it celebrates the economic potential of the difference, this theme seems to argue that smart and visionary companies will almost automatically make serious efforts to include a wide range of difference in their workforces and that those companies that fail to do so will be disciplined by the market because the performance of their employees will inevitably suffer.

However diversity promotion is not a simple task. Bond and Pyle (1998) cited various problems responsible for the lack of progress in the development of organizational diversity.

${ }^{1}$ Assistant Professor, Dept. of Psychology, K.N.C, University of Delhi 
They state that false assumptions about equality and difference lead to the development of diversity initiatives that generate unintended consequences, such as reverse discrimination that further exacerbates the workplace complications (Avery and Mckay, 2006). In our present environment women are to deal with stereotyped beliefs and unfavorable attitudes regarding her job, discrimination in opportunity and social pressure to fit her on feminine standard. These situations put her in a more vulnerable condition to experience stress in both working and non working status. Several studies report that men and women differ in the degree of stress. In a job that is considered female appropriate, it could be that the male feel stressed due to lack of approval as revealed in the study by Mitra and Sen (1993) that found that the male teachers faced more stress due to masculine sex role orientation. In another study it was found that, among bank employees, male reported more role stress (Barkat and Asma,1999; Mohammed et al. 2002)

In another study Triveni and Aminabhavi (2002) explored the gender differences among different professionals and the results revealed that women professionals experienced significantly higher occupational stress than men due to under participation. Studies confirm that women are more prone to stress than men (Beena and Poduval, 1992; Pradhan and Khattri, 2001). Tripathi and Bhattacharji (2012), studied the psychological stress among employed women and suggest that housework is exclusively considered as women's work that consequently increased work load on employed women.

Various job categories have been compared to capture the occupational stress among working women and similar level of stress is found in different professional groups but opposite results were found in a study conducted by Pandey and Srivastava(2000), who compared female personnel working in railway, bank and teaching institutions. Railway and bank employee experienced higher work stress than teachers. Degree of life stress and role stress experienced by different professional women also differ according to their field as Devi (2007) compared 180 women professional belonging to six occupational groups. The result showed science and technology professionals and doctors experienced greater life and role stress followed by administrators and self employed. Teachers and bankers experienced comparatively lesser stress in both role as well as life. The findings hint at the impact that gender typing of occupations has on the stress experienced by working women. The experiences of women in professions like science and technology, medicine etc that are considered to be more male typical are different from the experiences of women in more feminine occupations. Perhaps one of the causes behind the stress experienced by women in gender atypical occupations stem from their violation of gender prescriptions.

In another study that studied the psychological correlates of role stress in working women respondents belonging to different professional group such as researchers, doctors, nurses, social workers, school teachers, university and college teachers, gazetted officers, bank employee and women entrepreneurs were studied. The findings revealed that university and college teachers experienced least role stress. These jobs are considered socially appropriate for women, are prestigious, working hours are limited, vacations are frequent and pay scales are reasonable .Due to these reasons, women in these professions may be able to fulfill the demands of various roles that the society has prescribed for them and they may not experience conflict because of the multiple roles they are expected to play. School teachers were found to be lower on all kinds of role stress in comparison to other professional group where there is a transgression of societal prescriptions at some level. (Pareek and Mehta, 1997).

Workplace experiences in a so called diversity sensitive work setting is an issue that cannot be 
addressed in a socio cultural vacuum without considering the way females situate themselves vis a vis males at workplace and vice versa. Gender relations provide the psychosocial arenas in which these processes unfold. Gender relations have a profound effect on both men's and women's capacity to access and control resources and any information that sheds light on the causes, characteristics and consequences of unequal gender relations. The research in the present text attempts to amalgamate micro level structural concerns with macro context of gendered power play, cultural stereotypes with their inherent descriptive and prescriptive yardsticks in gaining a complete understanding workplace experience of male and female employees.

\section{THE PRESENT STUDY}

The purpose of the present study is to provide an insight into the impact of Gender, Proportional Numerical Strength at workplace and Occupational Gender Typing (in terms of Gender Typicality/ Atypicality) on the perception of stress and available coping resources.

\section{OBJECTIVES}

The objective of the study is to compare different groups created on the basis of Gender, Occupational Gender Type and Proportional Numerical Strength at workplace on the perception of stress and available coping resources.

\section{HYPOTHESIS}

On the basis of the review of literature and in the light of theoretical background, for attaining the objectives of research following hypothesis were formulated:

1. Hypothesis 1: There would be a significant difference between the eight groups based on Gender, Occupational Gender Type (Gender Atypical/ Gender Non Atypical) and Proportional Numerical Strength (Numerical Token/Non Token status) in the perceived level of stress.

2. Hypothesis 2: There would be a significant difference between the eight groups based on Gender, Occupational Gender Type (Gender Atypical/ Gender Non Atypical) and Proportional Numerical Strength (Numerical Token/Non Token status) in relation to the coping resources.

\section{METHOD}

\section{SAMPLE}

The sample comprised of both Male and Female employees working as numerical Tokens and Non Tokens in Gender atypical and Non atypical occupations. The total sample comprised of 250 participants.

The total sample can be divided into eight groups, namely Occupationally Gender Atypical Token Male (OATM), Occupationally Gender Atypical Token Female (OATF), Occupationally Gender Atypical Non Male(OANTM), Occupationally Gender Atypical Non Token Female(OANTF),Occupationally Gender Non Atypical Token Male (ONATM), Occupationally Gender Non Atypical Token Female (ONATF), Occupationally Gender Non Atypical Non Token Male (ONANTM), Occupationally Gender Non Atypical Non Token Female (ONANTF). The Sample design is illustrated in Figure 1. 


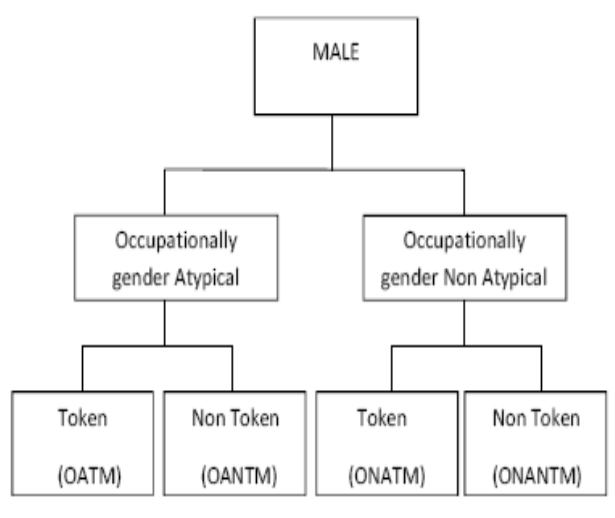

(35)

(30)

(26)

(35)

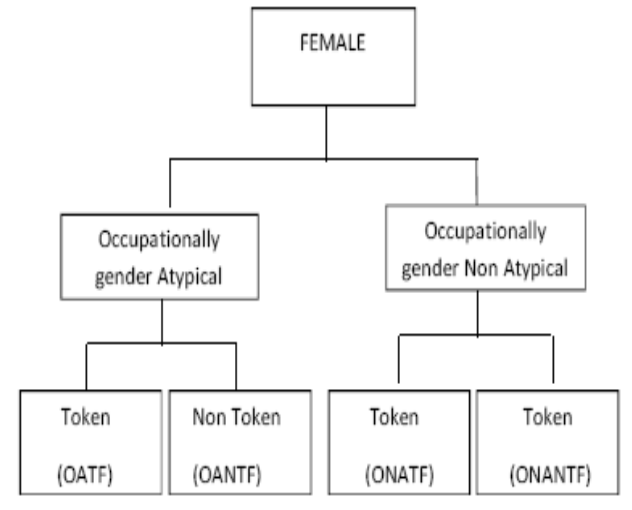

(32) (25)

(31)

(36)

Figure 1: Sample Design

The sample was selected for the eight categories on the basis of the statistics on Education and Vocational Training in India (2009-10) depicting specific vocations with their male-female proportional numerical strength of potential workforce. (Ministry of Statistics and Programme Implementation, 2013)

- Males: Gender atypical: less than 40\% ; Gender Non atypical: 40-60\%

Numerical Tokens: less than 20\%; Numerical Non Tokens: more than $40 \%$

- Females: Gender atypical: less than 30\% ; Gender Non atypical: 30-50\%

Numerical Tokens: less than 15\%; Numerical Non Tokens: more than $30 \%$

\section{Criterion for Inclusion}

Criteria 1: Number of years in the current job: 2-5

Criteria 2: Total work experience: $<=5$ years

Criteria 3: Education: Above Senior Secondary

Criteria 4: Work Sector: Organized

Criteria 5: Organization Size: Small ( $<50$ employees)

For all analyses, education and Total work experience as well as professional tenure in the current organization were controlled because workers with more experience and education may be rewarded with more challenging work, greater autonomy, and higher levels of compensation making them more satisfied with their overall work experience work and more strongly attached to the organization than are the inexperienced and less well educated.

\section{Research Tools}

\section{Perceived stress scale by Cohen (1983)}

The Perceived Stress Scale (PSS) is the most widely used psychological instrument for measuring the perception of stress. It is a measure of the degree to which situations in one's life are appraised as stressful. Items were designed to tap how unpredictable, uncontrollable, and overloaded respondents find their lives. The scale also includes a number of direct queries about current levels of experienced stress. PSS scores are obtained by reversing responses (e.g., $0=4$, $1=3,2=2,3=1 \& 4=0$ ) to the four positively stated items (items $4,5,7, \& 8$ ) and then 
summing across all scale items.

\section{Coping Resource Inventory by Marting\& Hammer (1987)}

Coping resource Inventory (CRI) was developed to provide a standardized measure of coping resources that may prove important in mediating a stress response. One of the goals for developing CRI was to identify the coping resources currently available to individuals for managing stress. The inventory comprises of the following dimensions:

1. Cognitive (COG): It assesses the extent to which individuals maintain a positive sense of self worth, a positive outlook towards others and optimism about life in general. A representative item in the inventory is "I feel as worthwhile as anyone else"

2. Social (SOC): It assesses the degrees to which individuals are imbedded in social networks that are able to provide support in terms of stress. A representative item is "I am a part f a group, other than my family, that cares about me"

3. Emotional (EMO):The degree to which individuals are able to accept and express a range of affect based on the premise that a range of emotional response aids in ameliorating long term consequences of stress. A representative item is " I can cry when sad "

4. Spiritual/Philosophical (S/P): The degree by which actions of individual are guided by stable and consistent values derived from religious, family or cultural traditions or from personal philosophy. A representative item in the inventory is "I know what is important in life".

5. Physical: It assesses the degrees to which individual's physical state of fitness and health are able to provide support in terms of stress.

\section{Quantitative Analysis}

Statistics used for analysing the quantitative data included simple descriptive statistics of mean and standard deviation.

Later for computing the differential perception of diversity climate of organisation for the 8 groups under study $2 * 2 * 2$ analysis of variance was employed. The 3 factors being Gender (Male/Female), Occupational Gender Type (Occupational Gender Atypicality/Non Atypicality) and Proportional (Male-Female) Numerical Strength (Token/Non Token status)

All analysis was conducted using SPSS, version 19. 


\section{RESULTS}

\section{TABLE 1}

Means and Standard Deviations for the Total Perception of stress for all the eight categories based on Gender, Occupational Gender Type and Proportional Numerical Strength at workplace.

\begin{tabular}{|l|c|c|}
\hline \multirow{2}{*}{\multicolumn{1}{|c|}{ CATEGORIES }} & \multicolumn{2}{c|}{$\begin{array}{c}\text { Total perception of } \\
\text { stress }\end{array}$} \\
\cline { 2 - 3 } & \multicolumn{2}{|c|}{ MEAN } \\
\hline OATM & 29.94 & 3.2 \\
\hline OANTM & 27.97 & 2.7 \\
\hline ONATM & 26.46 & 2.7 \\
\hline ONANTM & 25.23 & 4.05 \\
\hline OATF & 36.78 & 3.87 \\
\hline OANTF & 34.6 & 3.87 \\
\hline ONATF & 34.47 & 3.95 \\
\hline ONANTF & 28.76 & 2.33 \\
\hline
\end{tabular}

TABLE 1 shows that perceived stress reported by Occupationally atypical token females(OATF) is highest followed by Occupationally atypical non token females(OANTF) and then by Occupationally non atypical token females(ONATF), followed by Occupationally atypical token males(OATM), followed by Occupationally non atypical non token females(ONANTF), followed by Occupationally atypical non token males(OANTM). Then Occupationally non atypical token males (ONATM) and finally Occupationaly non atypical non token males(ONANTM).

TABLE 2

Summary result of Anova on the measure of Perceived Stress

\begin{tabular}{|l|c|c|c|c|}
\hline Source & $\begin{array}{c}\text { Type III } \\
\text { Sum of } \\
\text { Squares }\end{array}$ & Df & $\begin{array}{c}\text { Mean } \\
\text { Square }\end{array}$ & F \\
\hline Gender (A) & 2286.65 & 1 & 2286.65 & $108.208 * *$ \\
\hline Occutype (B) & 693.25 & 1 & 693.25 & $54.833 * *$ \\
\hline Numstatus (C) & 470.92 & 1 & 470.92 & $32.031 * *$ \\
\hline Gender * Occutype (A*B) & 14.42 & 1 & 14.42 & 1.251 \\
\hline Gender * Numstatus $(\mathrm{A} * \mathrm{C})$ & 82.13 & 1 & 82.13 & $7.3 * *$ \\
\hline Occutype * Numstatus $(\mathrm{B} * \mathrm{C})$ & 25.78 & 1 & 25.78 & 2.584 \\
\hline Gender * Occutype * Numstatus $(\mathrm{A} * \mathrm{~B} * \mathrm{C})$ & 30.041 & 1 & 30.041 & $6.077 * *$ \\
\hline
\end{tabular}


Perceived Stress and Coping Resources among Male and Female Employees in Diverse Workforces

\begin{tabular}{|l|l|l|l|}
\hline Total & 110612 & 250 & $\begin{array}{l}* \text { F Significant at 0.05 Level } \\
* * \text { F Significant at 0.01Level }\end{array}$ \\
\hline
\end{tabular}

Occutype- Occupational Gender Type, Numstatus- Proportional Numerical Strength

TABLE 2 shows that there exists a highly significant difference between the eight groups formulated on the basis of Gender, Occupational Gender Type and Proportional Numerical composition at workplace in their perceived stress as reflected in their significant interactional effects.

TABLE 3

Summary result of Anova on the measure of Available coping resources (depicting F values).

\begin{tabular}{|l|c|c|c|c|}
\hline Source & $\begin{array}{c}\text { Type III } \\
\text { Sum of } \\
\text { Squares }\end{array}$ & Df & $\begin{array}{c}\text { Mean } \\
\text { Square }\end{array}$ & F \\
\hline Gender (A) & 35681.796 & 1 & 35681.796 & $98.614 * *$ \\
\hline Occutype (B) & 3725.204 & 1 & 3725.204 & $10.2 * *$ \\
\hline Numstatus (C) & 2153.235 & 1 & 2153.235 & $6.807 * *$ \\
\hline Gender * Occutype (A*B) & 5505.302 & 1 & 5505.302 & $14.043 * *$ \\
\hline Gender * Numstatus $(\mathrm{A} * \mathrm{C})$ & 156.875 & 1 & 156.875 & 0.555 \\
\hline Occutype * Numstatus $(\mathrm{B} * \mathrm{C})$ & 3396.98 & 1 & 3396.98 & $9.492 * *$ \\
\hline Gender * Occutype * Numstatus $(\mathrm{A} * \mathrm{~B} * \mathrm{C})$ & 1043.256 & 1 & 1043.256 & $4.411^{*}$ \\
\hline Total & 100612 & 250 & $*$ F Significant at 0.05 Level \\
& & & $* *$ F Significant at 0.01Level \\
\hline
\end{tabular}

TABLE 3 shows that there exists a highly significant difference between the eight groups formulated on the basis of Gender, Occupational Gender Type and Proportional Numerical composition at workplace in their available coping resources as reflected in their significant interactional effects.

\section{DISCUSSION}

The present study attempts to fill in the gaps of the previous researches done in this area by providing an integrated approach to gain an insight into the probable intervening variables of Gender, Proportional (Male-Female) numerical strength at Workplace (Tokens/Non Tokens) and Occupational gender type (in terms of Gender Atypical/ Non Atypical or Neutral) on perceived stress and available coping resources.

The pattern of result hints at the need to understand the experiences of men and women at workplace beyond demographical structures of diversity. Table 2 shows that there exists a highly significant difference between the eight groups formulated on the basis of Gender, Occupational Gender Type and Proportional Numerical composition at workplace in their perceived workplace 
stress as reflected in their significant interactional effects thus confirming Hypothesis 1.Most of the previous gender based studies have explored the level of stress experienced by female employees in contrast to their male counterparts. Then with the current thrust on diversity promotion, many researchers tried to link the workplace experiences of employees with their relative numerical strength. One such attempt was by Kanter(1977), who in her theory of Tokenism discussed the workplace experiences of women minorities in contrast to male workplace majorities. According to the theory, in uniform groups, members and observers may never become self conscious about the common culture and type, which remain taken for granted and implicit. But the pressure of a person or two bearing a different set of social characteristics increases the self consciousness of the numerically dominant population and the consciousness of observers about what makes the dominants a class. This gives rise to three token dynamics: increased visibility of token minorities, isolation of token minorities and role encapsulation of token minorities. However a valuable insight is provided by the results of the present study. It's interesting to note that other than gender and relative numerical strength that have been more or less been the center of all such gender based research work in organizational set up, there is another factor that has been instrumental in affecting the perceived stress of male and female employees i.e. the gender typing of their occupation. The perceived stress, thus is getting affected by a mosaic of complex interactive forces of gender, numbers and stereotyping. The exclusive focus of various affirmative actions aiming to promote diversity at workplaces has been the numbers, but as can be seen in the obtained results, numbers or relative male- female numerical strength is just one part of the story. Till the time we take into account how males and females are situated in the macrocosm, what stereotypes, prescriptions and norms guide their behavior and determine their experiences, we would always arrive at a very lopsided understanding of the existing scenario.

Gender typing of occupations has an important bearing on the perceived stress level of individuals as the constant reminders about the gender atypicality of the choice of occupation both from the "insiders" working within the organisation and the "outsiders" who are part of the larger social network of which the organisation is a part, accentuates the perceived stress experienced by both males and females working in atypical jobs. Numerically few employees further feel lost in relation to their numerically major counterparts, however when these numerically few are treated as 'outsiders' in the very job itself by vitue of their 'atypical choice', matter worsens. However the situation is worst for females in gender atypical jobs as can be seen in the high mean scores for perceived stress for female tokens in gender atypical jobs(Table 1). Female employees are often damned as 'gender deviates' if they adhere to the prevalent 'masculine' job descriptions to get into the fold and are damned again if they adhere to their own feminine gender descriptions by getting labeled as misfit in the organizational functioning, thus increasing their level of perceived stress. However interestingly even in neutral jobs females didn't fare any better when they are numerically few in number as reflected in the low mean score of ONATF in comparison to males(as depicted in Table 1).

The findings are in line with Theory of Gendered Organizations (Acker, 1990) which argues that Males benefit from being male in a working world designed to reward stereotypically masculine attributes. As per Williams (1995) the cultural beliefs about masculinity and femininity are an integral part of the structure of the work world and serve to limit women's and enhance men's opportunities. According to the Williams/Acker theory, women do not face difficult times at workplace simply because they lack work experience, seniority, or other forms of human capital. Instead, or in addition, women are disadvantaged because the typical woman does not belong to 
the disembodied category of the ideal worker: one free from non-work (e.g., family) obligations and distractions. Also certain insights are provided by the theory of workplace Tokenism proposed by Kanter(1977) in terms of the processes resulting whenever a group is skewed such that a clearly definable subgroup. Kanter (1977) reported three interactional perceptual tendencies leading to negative token dynamics: Visibility that reflects the heightened attention directed toward Tokens, who always stand out in their work groups and thus suffer exacerbated pressures to perform, Contrast that refers to the exaggeration of differences between Tokens and the numeric majority, dominants, which may result in the Social Isolation of Tokens and finally, Assimilation that refers to the stereotyped perception of Tokens that may lead to Role Encapsulation at workplace in terms of the tasks and projects expected out of Tokens. As depicted in the results (Table 1), perceived stress by token males and females are relatively high in comparison to their non token counterparts clearly hinting at the possible impact the negative dynamics of heightened visibility, contrast and assimilation has on the perceived level of stress.

Similar patterns have been reflected with respect to available coping resources, as can be seen in Table 3, the eight groups show significant difference with respect to their perception with respect to available coping resources. The overall experience of any employee at workplace in terms of the level of stress perceived and the coping resources believed to be available is not affected by the gender of the employee alone, or by the numerical strength of their social group alone or by the gender appropriateness of their occupation in isolation rather it's an interactive effect of all these three factors that lead to the overall perception of stress and available coping resources. The present study has revealed that the overall perception of employees is embedded in the macro context created by socio cultural factors involving complex mosaic of status and power play between the genders and further the arena for this power play is set in the form of interactional contexts that constantly churn out these workplace experiences. Thus it is important for us to acknowledge that the way males and females are situated with respect to each other has important bearing on our attempts to achieve gender integration at the organizational level in the truest sense.

\section{IMPLICATIONS}

The empowerment initiatives taken up by our government are aimed to increase women representation in every sphere of life, in order to empower them and improve their workplace experiences. These initiatives with their exclusive focus on restoring numerical balance, draw heavily on the classic work of Rosabeth Moss Kanter (1977) and Drude Dahlerup(1988).However it's important to point out that Kanter's and Dahlerup's exclusive focus on numbers in terms of the 'critical mass' needed is just one part of the story. It's important to situate the stakeholders in the larger canvass and have a macro approach towards the issue of diversity.

\section{LIMITATIONS}

1. The present study consisted of roughly a sample size of 30 participants in each group. This sample size does not provide a safe basis for generalization of the findings of the study.

2. Generalizations are constrained since the sample was taken from few places in Delhi and NCR region only. As random sampling methods were not utilized, participants of this study are not representative.

3. Data was collected from different work organizations with different size, structure and work culture. 


\section{CONCLUSION}

The study offers an insight about how males and females are situated differently in our society and since workplaces are part of the larger societal structure only, there is a need to adopt a socio-organizational perspective to understand workplace dynamics in order to harness the potential of employees in a fruitful manner.

\section{REFERENCES}

1. Acker, J. (1990). Hierarchies, Occupations, Bodies: A Theory of Gendered Organizations. Gender and Society, 4, 139-158.

2. Avery, D. R., \& Mc Kay, P. F. (2006). Target practice: An organizational impression management approach to attracting minority and female job applicants. Personnel Psychology, 59, 157-187.

3. Barkat, S.A., \& Asma, P. (1999).Gender and age as determinants of organizational role stress. Journal of Community Guidance Research, 16, 141-145.

4. Bond, M. A., \& Pyle, T. L.(1998). Diversity dilemmas at work. Journal of Management Inquiry, 7, 252-269.

5. Chakraborty, S. (2013). Occupational Gender Segregation in India. Journal of Economics, 1(2), $1-31$.

6. Dahlerup, D. (1988) From a Small to a Large Minority: Women in Scandinavian Politics. Scandinavian Political Studies, 11 (4), 275-97.

7. Devi, A.S. (2007).Occupational Stress: A comparative study of women in different occupations. Prajnan, 35, 61-74.

8. Kanter, R.M. (1977). Men and Women of the Corporation. Basic Books, New York, NY.

9. Ministry of Statistics and Progamme Implementation (2013). Status of Education and vocational training in India, NSS 66th Round. Retrieved from http://mospi.nic.in/Mospi New/upload/nss report 551.pdf

10. Mitra, S.A., \& Sen, A.K. (1993).Executives under stress: A comparison between men and women. Journal of the Indian Academy of Applied Psychology, 19, 1-6.

11. Mohamed et al.(2002). Gender and Mental Health, Institute of Social Studies Trust, Ansar Institute of Psychological Medicine and Rehabilitation, Ansar Hospital Center for Development Studies.

12. Pandey, S., \& Srivastava, S. (2000).Coping with work stress: The Role of job category, family type and job tenure. Journal of Research and applications in Clinical Psychology, 3, 1-10.

13. Pareek, A., \& Mehta, M. (1997).Role stress among working women. In D.M. Pestonje and U. Pareek (ed.), Studies in Organizational Role Stress and Coping. Jaipur/New Delhi: Rawat publications.

14. Pizer, M., \& Hartel, C.E.J.(2004). For better or worse: Organisational Culture and emotions. In eds. C.E.J. Hartel, W.J. Zerbe \& N. M. Ashkanasy ,Mahwah, NJ, Emotions in Organisational behaviour Lawrence Erlbaum Associates, Inc. pp. 478-510.

15. Pradhan, M., \& Khatri, P.R. (2001). Intrapsychic and extra psychic production of burn out in doctors: Gender differences. Journal of Community Guidance \& Research, 18, 129-136.

16. Tripathi, P., \& Bhattacharjee, S. (2012).A study of Psychological Stress of Working Women. International journal of multidisciplinary research, Zenith, 2(2).

17. Triveni, S., \& Aminabhavi, V.A., (2002).Gender difference in occupational stress experience among professionals and non professionals. Journal of Community Guidance Research, 19, 1-7.

18. Williams, C. L. (1995). Still a man's world: Men who do women's work. Berkeley, CA: University of California Press. 